\title{
A comprehensive musculoskeletal and peripheral nervous system assessment of war-related bilateral upper extremity amputees
}

Mostafa Allami ${ }^{1}$, Batool Mousavi ${ }^{1}$, Mehdi Masoumi ${ }^{1}$, Ehsan Modirian ${ }^{2}$, Hadi Shojaei $^{{ }^{*},}$, Fatemeh Mirsalimi ${ }^{3}$, Maryam Hosseini ${ }^{1}$ and Pirouz Pirouzi ${ }^{4}$

\begin{abstract}
Background: Upper limb amputations are one of the unpleasant war injuries that armed forces are exposed to frequently.

The present study aimed to assess the musculoskeletal and peripheral nervous systems in Iraq-Iran war veterans with bilateral upper extremity amputation.

Methods: The study consisted of taking a history and clinical examinations including demographic data, presence and location of pain, level of amputation, passive and active ranges of movement of the joints across the upper and lower extremities and spine, manual palpation, neurological examination, blood circulation pulses and issues related to a prosthetic limb. In this study, 103 Iranian bilateral upper extremity amputees (206 amputations) from the Iran-Iraq war were evaluated, and a detailed questionnaire was also administered.

Results: The most common level of amputation was the finger or wrist level (108, 52.4\%). Based on clinical examination, we found high frequencies of limited active and passive joint range of movement across the scapula, shoulder, elbow, wrist and metacarpophalangeal, interphalangeal and thumb joints. Based on muscle strength testing, we found varying degrees of weakness across the upper limbs. Musculoskeletal disorders included epicondylitis (65, $31.6 \%)$, rotator cuff injury (24, $11.7 \%)$, bicipital tendonitis $(69,33.5 \%)$, shoulder drop (42, $20.4 \%)$ and muscle atrophy (19, 9.2\%). Peripheral nerve disorders included carpal tunnel syndrome in $13(6.3 \%)$ and unilateral brachial plexus injury in $1(1 \%)$. Fifty-three $(51.5 \%)$ were diagnosed with facet joint syndrome at the level of the cervical spine (the most frequent site). Using a prosthesis was reported by 65 (63.1\%), both left and right sides. The back was the most common site of pain (71.8\%).
\end{abstract}

Conclusion: The high prevalence of neuro-musculoskeletal disorders among bilateral upper extremity amputees indicates that they need regular rehabilitation care.

Keywords: Bilateral upper extremity amputation, Musculoskeletal disorder, Peripheral nerve injury, Pain, Iraq-Iran war

* Correspondence: hadsho@yahoo.com

'Janbazan Medical and Engineering Research Center (JMERC), Tehran, Iran

Full list of author information is available at the end of the article 


\section{Background}

For hundreds of years, wars have caused trauma to the limbs of soldiers, many of which result in amputation. The 8-year Iran-Iraq war was one of the longest military conflicts in the 20th century, which caused more than 1 million deaths and injuries including amputations [1]. Upper extremity amputation is one of these disastrous consequences, forcing many people to adapt to such injuries during their life [2]. Although surgical procedures on injured vessels, bones, nerves and other soft tissues has diminished the rate of amputation due to these injuries, amputation due to extremity trauma is still a main cause of morbidity in developing countries [3]. The cause of injury, socio-demographic characteristics of victims, treatment methods, infection rate and traumatic limb amputations occurring in battlefields are different from those in civilians. As war-related amputations happen mostly in young healthy persons, these unfortunate events can adversely affect the functional and physical health of the injured person, in addition to the mental and psychological sequelae that are associated with limb loss [4].

There are a few studies on the functional outcomes of amputees with upper limb amputation. These studies usually report the rates of employment, prosthesis use and demographic characteristics [5-9]. Literature on the assessment of the musculoskeletal system in "bilateral upper extremity amputation" is limited. Additionally, the generalization and comparability of the current data are often restricted by small sample sizes, different inclusion criteria and varying measures of consequences $[10,11]$.

There is also limited information about routine clinical examination of upper limb amputations. Successful prosthetic rehabilitation requires adequate muscle strength and normal joint motion $[12,13]$. Amputees with bilateral upper extremity amputation may need to accommodate for lost wrist, forearm and/or elbow motion by extreme motion at other articulations such as teeth, chin, and lower limbs to compensate for the loss of their hand/wrist function. The risk of musculoskeletal pain may increase because of these dysfunctional movements. Musculoskeletal pain and disorders often occur in upper limb amputations [14]. Pain and other grievances may affect physical function as well [15].

Compared to the war-related lower extremity amputations, war-related upper limb amputations are much more uncommon, and its reported rate varies from 12.5 to $18.5 \%$ across studies [1, 6-10]. Thus, there are few reports on long-term outcomes of veterans with upper limb amputation, particularly those with bilateral upper extremity amputation. As a result, some aspects of late outcomes of bilateral upper extremity amputation have not yet been well defined. This study aimed to describe clinically active and passive ranges of motion of upper extremity joints and muscle strength and to evaluate peripheral nerve and musculoskeletal disorders, distal upper extremity circulation, prosthesis use and pain of war-related bilateral upper limb amputees after more than 20 years since trauma.

\section{Methods}

This study was conducted to assess musculoskeletal and peripheral nervous system assessments of Iranian warrelated veterans with bilateral upper extremity amputation. For this purpose, a total of 140 veterans from across Iran were invited, and 103 (response rate, $73.6 \%$ ) participated. All participants were interviewed during a month. The data of the bilateral upper limb amputees was provided by the Veterans and Martyr Affair Foundation (VMAF) (VMAF offers health care services to the survivors of the 8-year Iraq-Iran war).

Each subject was visited by a fixed physical medicine and rehabilitation specialist for $2 \mathrm{~h}$. In all subjects, active and passive ranges of movement of joints (if applicable), neurological status including strength testing, sensory status, deep tendon reflexes, arterial pulses, and tenderness to palpation were assessed across the upper extremities. Active and passive joint range of motion included: elevation, depression, protraction and retraction across the scapula; flexion, extension, abduction, adduction, horizontal abduction, horizontal adduction, external rotation, internal rotation across the shoulder; flexion, extension, pronation and supination across the elbow; ulnar deviation, radial deviation, flexion and extension across the wrist; flexion, extension and abduction across the metacarpophalangeal joints; flexion across the interphalangeal joints; flexion, palmar abduction, radial abduction and opposition across the thumb. Joint range of movement was graded as "normal", "limited" and "not applicable" (due to the level of the amputation). Normal range of joint movement was determined according to the study by Gunal et al. [16]. Muscle strength was assessed using manual muscle testing and was categorized as "normal", "good", "fair/poor", "trace/without movement" [17]. On sensory examination, perception to light touch and pinprick were tested. Musculoskeletal disorders included bursitis, tendonitis, and epicondylitis, which were detected on palpation and used specific clinical tests. Shoulder rotator cuff injury was detected based on shoulder specific tests. Tinel's sign across the elbow and wrist, and phalen's test were performed (if applicable). Cervical and lumbar range of movement tests were performed as well as palpation on the spine midline and on the facet joints. Shoulder drop and muscle atrophy were diagnosed by inspection. Deep tendon reflexes were assessed in the upper extremities, if applicable, using a hammer reflex tool. Radial and ulnar pulses were obtained via palpation and compared bilaterally, if applicable. Types of prosthetics use were also surveyed. Presence and location of 
musculoskeletal pain, phantom sensation and phantom pain were also asked. The subjects were asked about all the above mentioned problems simultaneously. The data for each patient were collected and entered into SPSS for Windows 22.0 (SPSS Inc., Chicago, IL., USA) for further analysis. The study was approved by the ethical committee of Janbazan Medical and Engineering Research Center (JMERC), Tehran, Iran.

\section{Results}

Almost all the subjects were male (102, $99.0 \%)$. Of 206 upper limb amputations, $52.4 \%(n=108)$ were at the finger or wrist, $39.8 \%(n=82)$ at the elbow and $7.8 \%(n=16)$ at the transhumeral or higher level. The mean age at the time of injury was $20.8 \pm 7.6$ years, and the mean age at followup was $37.5 \pm 10.0$ years. Duration of injury was approximately $16.9 \pm 5.8$ years. More than half of the participants $(n=61,59.2 \%)$ reported an education of 12th grade or higher, and $88.3 \%(n=91)$ of them were married. Details of the additional war-related injuries, obtained from their records, are listed in Table 1.

Sixty-five (63.1\%) cases reported using a prosthesis, and $20(30.8 \%)$ of them used their devices for $\geq 8 \mathrm{~h}$ per day. The following types of prosthesis were employed by our subjects: myoelectric (41, $39.8 \%$ ), cosmetic (22, $21.4 \%)$, body powered (13, $12.6 \%)$ and hybrid (3, $2.9 \%)$. The back was the most common site of pain $(71.8 \%)$, followed by the lower limbs (Fig. 1). Phantom sensation was reported by 91 (88.3\%), and phantom pain was experienced by 61 (59.2\%) participants.

Limitations in passive ranges of motion including the scapula $(n=10,1.2 \%)$, shoulder $(n=23,1.5 \%)$, elbow $(n=4,0.6 \%)$, wrist $(n=59,38.3 \%)$, metacarpophalangeal joint $(n=39,52.7 \%)$, interphalangeal joint $(n=23$, $47.9 \%)$ and thumb $(n=51,51.5 \%)$ in bilateral upper limb amputees are shown in Table 2. Additionally, limitations in active ranges of motion in the scapula $(n=32$, $7.9 \%)$, shoulder ( $n=118,0.08 \%)$, elbow ( $n=13,1.8 \%)$, wrist $(n=73,48.3 \%)$, metacarpophalangeal joint $(n=46$,

Table 1 Additional war-related injuries in bilateral upper extremity amputees $(n=103)$

\begin{tabular}{lllll}
\hline Type of injury & Left & Right & Bilateral & Total (\%) \\
\hline Without injuries & - & - & - & $3(2.9)$ \\
Head and Neck & - & - & - & $43(41.7)$ \\
Eyes & 11 & 8 & 50 & $69(67.0)$ \\
Ears & 8 & 7 & 41 & $56(54.4)$ \\
Lower limb & 25 & 22 & 11 & $58(56.3)$ \\
Trunk of the body & - & - & - & $53(51.5)$ \\
Spinal cord & - & - & - & $30(29.1)$ \\
Chemical exposure & - & - & - & $6(5.8)$ \\
\hline
\end{tabular}

$63.0 \%)$, interphalangeal joint $(n=29,60.4 \%)$ and thumb $(n=63,60.6 \%)$ in bilateral upper limb amputees are detailed in Table 3. The most limitations in passive joint movement were found in the thumb, interphalangeal and metacarpophalangeal joints (Table 2). Additionally, the most limitation in active range of motion was observed in the thumb, interphalangeal, metacarpophalangeal and wrist joints.

Limited muscle strength was found as follows: scapula ( $n=95,12.0 \%)$, shoulder $(n=219,14.6 \%)$, elbow joints ( $n=68,9.9 \%)$, wrist $(n=63,52.5 \%)$, metacarpophalangeal joint $(n=34,61.8 \%)$, interphalangeal joint $(n=22$, $61.1 \%)$ and thumb $(n=52,68.4 \%)$ (Table 4$)$.

The most common finding among all musculoskeletal problems was bicipital tendonitis $(n=69,33.5 \%)$. Epicondylitis was also frequently discovered $(65,31.6 \%)$. Rotator cuff injury was another issue found in 24 participants $(11.7 \%)$, with the same frequency in the right and the left sides. Shoulder bursitis was observed in 2 participants $(1.0 \%)$ without elbow bursitis in any subject. Additionally, shoulder drop was found in 42 (20.4\%) subjects. Muscle atrophy was less common compared with the other problems $(n=19,9.2 \%)$.

Fifty-three $(51.5 \%)$ cases had facet joint syndrome at the level of the cervical spine; 13 (12.6\%) cases at the level of the lumbar spine and only $1(1 \%)$ case at the level of the thoracic spine. Regarding peripheral nerve injuries, carpal tunnel syndrome symptoms were found in 13 participants (6.3\%), and unilateral brachial plexus injury was only observed in 1 (1\%) case. Weak distal upper extremity circulation was only observed in $1(1.0 \%)$ subject.

\section{Discussion}

After more than 20 years of disability, war-related bilateral upper limb amputees were all visited by a PM\&R specialist. Our findings revealed that a considerable amount of these subjects suffered from musculoskeletal disorders and pain. Most of the subjects were young at the time of casualty and had additional injuries, especially in their lower limbs.

More distal amputation was associated with a higher rate of small joint limitation. Muscle strength in the shoulder and elbow joints was consistent with previous results, which may be due to having the same measurements. Most cases did not have any movement problems in their other joints, and limited joint motion in other parts of the body was observed in the lumbar region, ankle, and foot which was in contrast with a study that reported that mobility of the neck joint was reduced bilaterally [18].

Approximately two-thirds of the survivors suffered from pain in various parts of their bodies, especially back pain, which was followed by knee pain. Consistent with our results, back pain in upper limb amputees was reported as 
the most common complaint in up to more than half of the participants [15]. Moreover, consistent with previous results, more than three-quarters of our cases experienced phantom sensation [7]. Phantom pain was found in approximately two-thirds of participants, which was in accordance with the estimates of previous studies of 50 to $90 \%$ in upper limb amputees [15, 19-21]. As pain control is important for patient comfort and health, prevention and treatment of pain can play a significant role in upper limb amputation rehabilitation.

The greatest limitation in passive and active joint movement was found in the thumb and interphalangeal and metacarpophalangeal joints. Similarly, metacarpophalangeal, interphalangeal and thumb joints demonstrated the weakest muscle strength, which emphasized the importance of exercises to use these muscles. The results of the unilateral upper limb amputees' survey indicated active joint motion, especially in shoulder flexion, was limited, whereas forearm rotation and muscle strength were less limited [18]. Regarding range of motion of joints, scapula retraction, shoulder abduction, elbow pronation and supination and wrist ulnar and radial deviation were the dominant limited movements due to muscle contracture.

According to the musculoskeletal and peripheral nerve examinations, bicipital tendonitis was the most prevalent complication found in approximately one-third of the subjects. Lateral epicondylitis was the next most frequent complication observed. Development of bicipital tendonitis and lateral epicondylitis indicated elbow joint overuse in subjects with elbow amputation. The elbow is susceptible to repeated stresses, and the development of bicipital tendonitis and lateral epicondylitis due to overuse can occur [22].

There is limited research on overuse syndrome in bilateral upper limb amputation, which is associated with rotator cuff injuries including tendonitis and tears, shoulder impingement, and bursitis $[14,15,23]$. Additionally, rotator cuff syndrome and lateral epicondylitis on the nonamputated side were more common than in previous studies [14]. As the frequency of below elbow amputation was higher than above elbow amputation, a higher prevalence of epicondylitis was predictable. In a report of peripheral nerve problems in bilateral upper limb amputation, carpal tunnel syndrome was estimated to occur in more than one-fourth of proximal upper limb amputees [24]. The occurrence of carpal tunnel syndrome in the present study was estimated to be more than one-third, which is higher than that in previous studies on bilateral and unilateral upper limb amputees [14, 24]. Moreover, musculoskeletal disorders were more prominent than peripheral nerve injuries among bilateral upper limb amputees. We found no previous report in our literature review regarding facet joint syndrome in the cervical spine using symptoms and signs including neck pain, local spine tenderness and decreased range of motion, which was the next most common musculoskeletal disorder in our subjects.

Global prosthesis use has been estimated to be up to $80 \%$, and two-thirds of participants in a previous study employed the prosthesis for $\geq 8 \mathrm{~h} /$ day $[12,15,21]$. In contrast, prosthesis use was less frequent in the participants in this study, and only one-quarter employed prosthesis for $\geq 8 \mathrm{~h} /$ day. The use of myoelectric versus cosmetic prostheses can increase actual prosthesis use in activities of daily living (ADL) [21]. In contrast, rejection of prosthesis use was reported because of poor cosmetic quality of some types of devices. Additionally, unilateral upper limb amputees prefer cosmetic hands, whereas among bilateral upper limb amputees, hook hands and functional hands were the most frequently used types of prosthetic limbs [15]. Unlike previous results, the most prevalent types of prosthetic limbs currently used by our participants included myoelectric and cosmetic hands.

\section{Limitations}

The time limit was a substantial issue in obtaining a comprehensive pain investigation including pain inventory scale and visual analog scale. We also did not have a

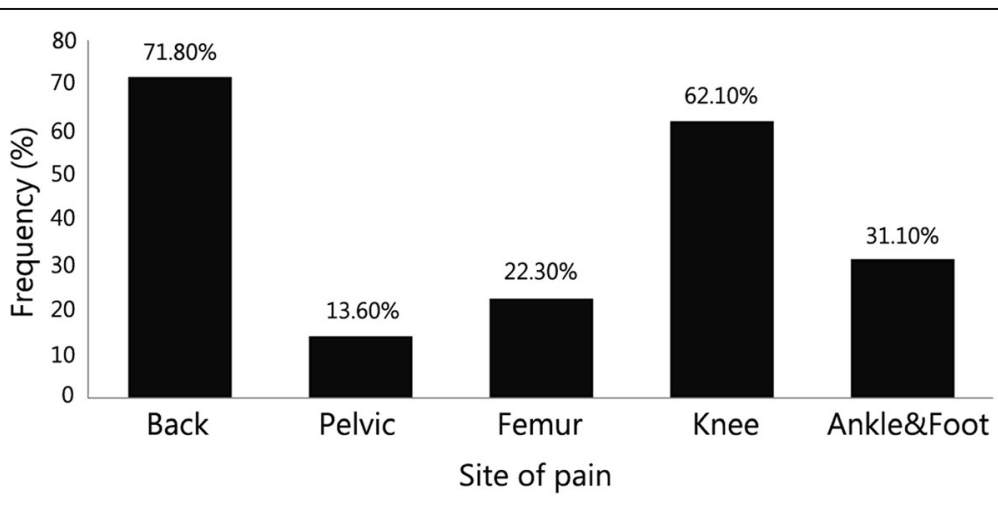

Fig. 1 Distribution of pain in bilateral upper limb amputees 
Table 2 Passive range of motion of upper extremity joints in bilateral upper limb amputees $(n=103)$

\begin{tabular}{|c|c|c|c|c|c|c|c|c|}
\hline \multirow[t]{2}{*}{ Joint } & \multicolumn{3}{|c|}{ Right side } & \multicolumn{3}{|l|}{ Left side } & \multicolumn{2}{|c|}{ Unilateral/Bilateral limited } \\
\hline & Limited & Normal & $N A^{a}$ & Limited & Normal & NA & $\bar{n}$ & $\%^{\mathrm{b}}$ \\
\hline \multicolumn{9}{|l|}{ Scapula } \\
\hline Elevation & 0 & 100 & 3 & 0 & 101 & 2 & 0 & 0 \\
\hline Depression & 0 & 100 & 3 & 1 & 100 & 2 & 0 & 0 \\
\hline Protraction & 1 & 99 & 3 & 2 & 99 & 2 & 1 & 1.0 \\
\hline Retraction & 2 & 98 & 3 & 4 & 97 & 2 & 2 & 2.0 \\
\hline \multicolumn{9}{|l|}{ Shoulder } \\
\hline Flexion & 0 & 96 & 7 & 1 & 97 & 5 & 0 & 0 \\
\hline Extension & 1 & 95 & 7 & 1 & 96 & 6 & 0 & 0 \\
\hline Abduction & 4 & 92 & 7 & 3 & 94 & 6 & 3 & 3.0 \\
\hline Adduction & 0 & 96 & 7 & 0 & 97 & 6 & 0 & 0 \\
\hline Horizontal abduction & 1 & 95 & 7 & 2 & 95 & 6 & 1 & 1.0 \\
\hline Horizontal adduction & 0 & 94 & 9 & 2 & 95 & 6 & 0 & 0 \\
\hline External rotation & 2 & 94 & 7 & 2 & 95 & 6 & 1 & 1.0 \\
\hline Internal rotation & 2 & 92 & 9 & 2 & 95 & 6 & 1 & 1.0 \\
\hline \multicolumn{9}{|l|}{ Elbow } \\
\hline Flexion & 0 & 88 & 15 & 0 & 89 & 14 & 0 & 0 \\
\hline Extension & 0 & 88 & 15 & 0 & 89 & 14 & 0 & 0 \\
\hline Pronation & 1 & 85 & 17 & 1 & 85 & 17 & 0 & 0 \\
\hline Supination & 1 & 84 & 18 & 1 & 84 & 18 & 0 & 0 \\
\hline \multicolumn{9}{|l|}{ Wrist } \\
\hline Ulnar deviation & 8 & 12 & 83 & 8 & 10 & 85 & 3 & 10.7 \\
\hline Radial deviation & 8 & 13 & 82 & 7 & 11 & 85 & 3 & 10.3 \\
\hline Flexion & 7 & 14 & 82 & 7 & 11 & 85 & 3 & 10.3 \\
\hline Extension & 7 & 13 & 83 & 7 & 11 & 85 & 3 & 10.7 \\
\hline \multicolumn{9}{|l|}{ Metacarpophalangeal } \\
\hline Flexion & 6 & 7 & 90 & 7 & 6 & 90 & 2 & 10.0 \\
\hline Extension & 6 & 7 & 90 & 6 & 6 & 91 & 2 & 10.5 \\
\hline Abduction & 8 & 4 & 91 & 6 & 5 & 92 & 2 & 13.3 \\
\hline \multicolumn{9}{|l|}{ Interphalangeal } \\
\hline Flexion of proximal interphalangeal & 6 & 7 & 90 & 5 & 6 & 92 & 2 & 11.1 \\
\hline Extension of distal interphalangeal & 6 & 7 & 90 & 6 & 5 & 92 & 2 & 11.1 \\
\hline \multicolumn{9}{|l|}{ Thumb } \\
\hline Metacarpophalangeal flexion & 5 & 7 & 91 & 5 & 5 & 93 & 1 & 5.9 \\
\hline Interphalangeal flexion & 5 & 6 & 92 & 5 & 5 & 93 & 1 & 6.2 \\
\hline Palmar abduction & 5 & 5 & 93 & 6 & 4 & 93 & 1 & 6.7 \\
\hline Radial abduction & 6 & 4 & 93 & 6 & 3 & 94 & 1 & 6.7 \\
\hline Opposition & 5 & 4 & 94 & 4 & 4 & 95 & 1 & 7.1 \\
\hline
\end{tabular}

${ }^{\mathrm{a}}$ Not applicable; ${ }^{\mathrm{b}}$ The percent was calculated according to the number of applicable cases

psychologist to perform physical body assessments. We had no access to EMG/NCS, ultrasound or X-rays at the time of the assessments. We also had no access to the records of their past medical visits or rehabilitation services to compare with their current conditions.

\section{Recommendation}

Further studies of subjects who had brachial plexopathy/ peripheral neuropathy should investigate the reasons for non-use of particular types of prostheses, and training on the use of the prosthesis seems necessary. 
Table 3 Active range of motion of upper extremity joints in bilateral upper limb amputees $(n=103)$

\begin{tabular}{|c|c|c|c|c|c|c|c|c|}
\hline \multirow[t]{2}{*}{ Joint } & \multicolumn{3}{|c|}{ Right side } & \multicolumn{3}{|l|}{ Left side } & \multicolumn{2}{|c|}{ Unilateral/Bilateral limited } \\
\hline & Limited & Normal & $N A^{a}$ & Limited & Normal & NA & $n$ & $\%^{\mathrm{b}}$ \\
\hline \multicolumn{9}{|l|}{ Scapula } \\
\hline Elevation & 1 & 100 & 2 & 0 & 101 & 2 & 0 & 0 \\
\hline Depression & 2 & 99 & 2 & 1 & 100 & 2 & 1 & 1.0 \\
\hline Protraction & 3 & 97 & 3 & 6 & 95 & 2 & 2 & 2.0 \\
\hline Retraction & 9 & 92 & 2 & 10 & 91 & 2 & 2 & 2.2 \\
\hline \multicolumn{9}{|l|}{ Shoulder } \\
\hline Flexion & 4 & 92 & 7 & 4 & 94 & 5 & 2 & 2.0 \\
\hline Extension & 4 & 92 & 7 & 5 & 92 & 6 & 2 & 2.0 \\
\hline Abduction & 15 & 82 & 6 & 13 & 84 & 6 & 8 & 8.0 \\
\hline Adduction & 3 & 94 & 6 & 3 & 94 & 6 & 1 & 1.0 \\
\hline Horizontal abduction & 10 & 86 & 7 & 9 & 88 & 6 & 5 & 5.0 \\
\hline Horizontal adduction & 2 & 95 & 6 & 3 & 94 & 6 & 1 & 1.0 \\
\hline External rotation & 12 & 84 & 6 & 9 & 88 & 6 & 6 & 6.0 \\
\hline Internal rotation & 13 & 84 & 7 & 9 & 88 & 6 & 6 & 6.0 \\
\hline \multicolumn{9}{|l|}{ Elbow } \\
\hline Flexion & 1 & 88 & 14 & 1 & 88 & 14 & 0 & 0 \\
\hline Extension & 1 & 88 & 14 & 2 & 87 & 14 & 0 & 0 \\
\hline Pronation & 2 & 85 & 16 & 2 & 84 & 17 & 0 & 0 \\
\hline Supination & 2 & 84 & 17 & 2 & 83 & 18 & 0 & 0 \\
\hline \multicolumn{9}{|l|}{ Wrist } \\
\hline Ulnar deviation & 11 & 10 & 82 & 9 & 9 & 85 & 4 & 14.3 \\
\hline Radial deviation & 10 & 10 & 83 & 9 & 9 & 85 & 4 & 13.8 \\
\hline Flexion & 7 & 12 & 84 & 9 & 9 & 85 & 4 & 13.8 \\
\hline Extension & 9 & 10 & 84 & 9 & 9 & 85 & 4 & 14.3 \\
\hline \multicolumn{9}{|l|}{ Metacarpophalangeal } \\
\hline Flexion & 7 & 6 & 90 & 8 & 5 & 90 & 2 & 10.0 \\
\hline Extension & 7 & 6 & 90 & 8 & 4 & 91 & 2 & 10.5 \\
\hline Abduction & 9 & 3 & 91 & 7 & 3 & 93 & 2 & 13.3 \\
\hline \multicolumn{9}{|l|}{ Interphalangeal } \\
\hline Flexion of proximal interphalangeal & 7 & 6 & 90 & 7 & 4 & 92 & 2 & 11.1 \\
\hline Extension of distal interphalangeal & 7 & 6 & 90 & 8 & 3 & 92 & 2 & 11.1 \\
\hline \multicolumn{9}{|l|}{ Thumb } \\
\hline Metacarpophalangeal flexion & 8 & 5 & 90 & 5 & 5 & 93 & 1 & 5.9 \\
\hline Interphalangeal flexion & 8 & 4 & 91 & 5 & 5 & 93 & 1 & 6.2 \\
\hline Palmar abduction & 7 & 4 & 92 & 6 & 4 & 93 & 1 & 6.7 \\
\hline Radial abduction & 7 & 4 & 92 & 6 & 3 & 94 & 2 & 13.3 \\
\hline Opposition & 6 & 4 & 93 & 5 & 3 & 95 & 2 & 14.3 \\
\hline
\end{tabular}

${ }^{\mathrm{a}}$ Not applicable; ${ }^{\mathrm{b}}$ The percent was calculated according to the number of applicable cases

\section{Conclusions}

This study found varying frequencies of limited active and passive ranges of movement and muscle strength among bilateral upper limb amputees. Our findings have shown that bilateral upper limb amputees are at high risk of neuromusculoskeletal disorders, including lower back pain, lower extremity pain, cervical pain, soft tissue problems such as tendinitis and bursitis in the shoulder, phantom limb pain and sensation, and carpal tunnel syndrome. This research will help primary health providers identify upper limb 
Table 4 Upper extremity muscle strength in bilateral upper limb amputees $(n=206)$

\begin{tabular}{|c|c|c|c|c|c|c|c|c|c|c|}
\hline \multirow[t]{2}{*}{ Joint } & \multicolumn{4}{|c|}{ Right side } & \multicolumn{4}{|c|}{ Left side } & \multicolumn{2}{|c|}{ Total limited } \\
\hline & Normal & Good & Fair/Poor & Trace/None & Normal & Good & Fair/Poor & Trace/None & $n$ & $\%^{a}$ \\
\hline \multicolumn{11}{|l|}{ Scapula } \\
\hline Elevation & 93 & 7 & 0 & 1 & 87 & 10 & 0 & 0 & 18 & 9.1 \\
\hline Depression & 92 & 8 & 0 & 1 & 86 & 11 & 0 & 0 & 20 & 10.1 \\
\hline Protraction & 89 & 8 & 0 & 3 & 83 & 7 & 5 & 2 & 25 & 12.6 \\
\hline Retraction & 86 & 11 & 1 & 3 & 79 & 9 & 6 & 2 & 32 & 16.1 \\
\hline \multicolumn{11}{|l|}{ Shoulder } \\
\hline Flexion & 86 & 9 & 0 & 1 & 83 & 8 & 2 & 0 & 20 & 10.8 \\
\hline Extension & 85 & 10 & 0 & 1 & 82 & 8 & 2 & 0 & 21 & 11.3 \\
\hline Abduction & 77 & 15 & 2 & 1 & 77 & 11 & 4 & 0 & 33 & 17.7 \\
\hline Adduction & 84 & 9 & 1 & 1 & 79 & 9 & 3 & 0 & 24 & 12.4 \\
\hline Horizontal abduction & 82 & 11 & 2 & 1 & 78 & 9 & 4 & 0 & 27 & 14.5 \\
\hline Horizontal adduction & 83 & 11 & 0 & 1 & 78 & 9 & 3 & 0 & 24 & 12.9 \\
\hline External rotation & 75 & 16 & 3 & 1 & 77 & 11 & 3 & 1 & 35 & 18.8 \\
\hline Internal rotation & 74 & 16 & 3 & 1 & 77 & 11 & 3 & 1 & 35 & 18.8 \\
\hline \multicolumn{11}{|l|}{ Elbow } \\
\hline Flexion & 78 & 6 & 1 & 2 & 75 & 8 & 0 & 1 & 18 & 10.5 \\
\hline Extension & 78 & 6 & 1 & 2 & 75 & 8 & 0 & 1 & 18 & 10.5 \\
\hline Pronation & 76 & 5 & 1 & 1 & 71 & 9 & 0 & 1 & 17 & 10.4 \\
\hline Supination & 76 & 4 & 1 & 1 & 71 & 8 & 0 & 1 & 15 & 9.3 \\
\hline \multicolumn{11}{|l|}{ Wrist } \\
\hline Ulnar deviation & 7 & 3 & 1 & 5 & 7 & 2 & 0 & 5 & 16 & 53.3 \\
\hline Radial deviation & 7 & 3 & 1 & 5 & 7 & 2 & 0 & 5 & 16 & 53.3 \\
\hline Flexion & 7 & 5 & 0 & 4 & 7 & 2 & 0 & 5 & 16 & 53.3 \\
\hline Extension & 8 & 4 & 1 & 3 & 7 & 2 & 0 & 5 & 15 & 50.0 \\
\hline \multicolumn{11}{|l|}{ Metacarpophalangeal } \\
\hline Flexion & 4 & 1 & 2 & 4 & 3 & 0 & 2 & 4 & 13 & 65.0 \\
\hline Extension & 4 & 1 & 2 & 4 & 3 & 0 & 2 & 3 & 12 & 63.2 \\
\hline Abduction & 4 & 0 & 3 & 3 & 3 & 0 & 1 & 2 & 9 & 56.3 \\
\hline \multicolumn{11}{|l|}{ Interphalangeal } \\
\hline Flexion of proximal interphalangeal & 4 & 0 & 3 & 4 & 3 & 0 & 2 & 2 & 11 & 61.1 \\
\hline Extension of distal interphalangeal & 4 & 0 & 4 & 3 & 3 & 0 & 2 & 2 & 11 & 61.1 \\
\hline \multicolumn{11}{|l|}{ Thumb } \\
\hline Metacarpophalangeal flexion & 3 & 1 & 4 & 2 & 2 & 0 & 1 & 3 & 11 & 68.8 \\
\hline Interphalangeal flexion & 2 & 1 & 4 & 2 & 2 & 0 & 1 & 3 & 11 & 73.3 \\
\hline Palmar abduction & 2 & 1 & 3 & 2 & 3 & 0 & 1 & 3 & 10 & 66.7 \\
\hline Radial abduction & 2 & 1 & 3 & 2 & 3 & 0 & 1 & 3 & 10 & 66.7 \\
\hline Opposition & 2 & 0 & 3 & 3 & 3 & 0 & 1 & 3 & 10 & 66.7 \\
\hline
\end{tabular}

${ }^{\text {a }}$ The percent was calculated according to the number of applicable cases

amputees with high rehabilitation needs. We recommend more studies to investigate clinical examinations and the effect of prosthesis wear on the musculoskeletal system in bilateral upper limb amputees. Encouragement to do regular appropriate exercises and routine visits by specialists seems to be necessary in this population. Moreover, counseling these subjects about the risks of musculoskeletal disorders seems to be essential. Additionally, encouragement of family members to maintain their emotional support and have good relationships with them would be helpful. We also recommend more studies on pain syndromes in bilateral upper limb amputees and psychological aspects of pain. 


\section{Abbreviations}

ADL: activity of daily living; EMG/NCS: electromyography/nerve conduction study; JMERC: Janbazan medical and engineering research center; NA: not applicable; PM\&R: physical medicine and rehabilitation; SPSS: statistical package for the social sciences; VMAF: veterans and martyr affair foundation

\section{Acknowledgments}

The authors are grateful to the Veterans and Martyrs Affair Foundation (VMAF) and Janbazan Medical and Engineering Research Center (JMERC) for funding the survey.

\section{Availability of data and material}

All data generated or analyzed during this study are included in this published article.

\section{Authors' contributions}

MA, BM, MM, EM and HS performed data gathering by direct patient visit or in face-to-face interviews. FM, MH and PP performed the statistical analysis and wrote the paper to the final draft stage. All authors read and approved the final manuscript.

\section{Competing interests}

The authors declare that they have no competing interests.

\section{Ethics approval and consent to participate}

Our research protocol was submitted for consideration, comment, guidance and approval to the research ethics committee of Veterans and Martyr Affair Foundation (VMAF) and was approved before the study began. Participation in the study was voluntary, and written informed consent was obtained from each participant after a full explanation of the study.

\section{Author details}

${ }^{1}$ Janbazan Medical and Engineering Research Center (JMERC), Tehran, Iran. 2Emergency Medicine, School of Medicine, Qazvin University of Medical Sciences, Qazvin, Iran. ${ }^{3}$ Candidate of Health Education and Promotion, Department of Health Education and Promotion, Faculty of Medical Sciences, Tarbiat Modares University, Tehran, Iran. ${ }^{4}$ Department of Radiology, Imam Hospital, Tehran University of Medical Sciences, Tehran, Iran.

Received: 23 November 2015 Accepted: 10 October 2016

\section{Published online: 15 November 2016}

\section{References}

1. Rayegani SM, Aryamehr A, Soroosh MZ, Baghbani M. Phantom pain, phantom sensation, and spine pain in bilateral lower limb amputees: results of a national survey of Iraq-Iran War victims. JPO. 2010;22(3):162-5.

2. Ebrahimzadeh MH, Fattahi AS. Long-term clinical outcomes of Iranian veterans with unilateral transfemoral amputation. Disabil Rehabil. 2009; 31(22):1873-7.

3. Moini M, Rasouli MR, Khaji A, Farshidfar F, Heidari P. Patterns of extremity traumas leading to amputation in Iran: results of Iranian National Trauma Project. Chin J Traumatol. 2009;12(1):77-80.

4. Taghipour H, Moharamzad Y, Mafi AR, Amini A, Naghizadeh MM, Soroush $M R$, et al. Quality of life among veterans with war-related unilateral lower extremity amputation: a long-term survey in a prosthesis center in iran. Orthop Trauma. 2009:23:525-30.

5. Lindner HYN, Natterlund BS, Hermansson LMN. Upper limb prosthetic outcome measures: review and content comparison based on International Classification of Functioning, Disability and Health. Prosthet Orthot Int. 2010;34:109-28.

6. Sabzi AS, Taheri AA. Amputation: A ten-year survey. Trauma Mon. 2013;18(3):126-9.

7. Jang $\mathrm{CH}$, Yang $\mathrm{HS}$, Yang HE, Lee SY, Kwon JW, Yun BD, et al. A survey on activities of daily living and occupations of upper extremity amputees. Ann Rehabil Med. 2011;35(6):907-21.

8. Bostmans JC, Geertzen JH, Post WJ, van der Schans CP, Dijkstra PU. Factors associated with phantom limb pain: a 31/2-year prospective study. Clin Rehabil. 2010;24(5):444-53

9. MCFarland LV Winkler SLH, Heinemann AW, Jones M, Esquenazi A Unilateral upper-limb loss: satisfaction and prosthetic-device use in veterans and servicemembers from Vietnam and OIF/OEF conflicts. J Rehabil Res Dev. 2010:47:299-316.

10. Roth ES, Buck DG, Gorantla VS, Losee JE, Foust DE, Britton CA. The role of imaging in patient selection, preoperative planning, and postoperative monitoring in human upper extremity allotransplantation. J Transplant. 2014;2014:169546.

11. Gabl M, Kröpfl A. Subjective impairment after macroamputation of the upper extremity. Handchir Mikrochir PlastChir. 2008;40:31-4.

12. Dudkiewicz I, Gabrielov R, Seiv-Ner I, Zelig G, Heim M. Evaluation of prosthetic usage in upper limb amputees. Disabil Rehabil. 2004;26:60-3.

13. Resnik L, Meucci MR, Lieberman-Klinger S, Fantini C, Kelty DL, Disla R, et al. Advanced upper limb prosthetic devices: implications for upper limb prosthetic rehabilitation. Arch Phys Med Rehabil. 2012;93(4):710-7.

14. Ostlie K, Franklin RJ, Skjeldal OH, Skrondal A, Magnus P. Musculoskeletal pain and overuse syndromes in adult acquired major upper-limb amputees. Arch Phys Med Rehabil. 2011;92(12):1967-73.

15. Hanley MA, Ehde DM, Jensen M, Czerniecki J, Smith DG, Robinson LR. Chronic pain associated with upper-limb loss. Am J Phys Med Rehabil. 2009;88:742-51.

16. Gunal I, Kose N, Erdogan O, Gokturk E, Seber S. Normal range of motion of the joints of the upper extremity in male subjects, with special reference to side. J Bone Joint Surg Am. 1996;78:1401-4.

17. Yang JF, Norton J, Nevett-Duchcherer J, Roy FD, Gross DP, Gorassini MA Volitional muscle strength in the legs predicts changes in walking speed following locomotor training in people with chronic spinal cord injury. Phys Ther. 2011;91(6):931-43.

18. Østlie K, Franklin RJ, Skjeldal OH, Skrondal A, Magnus P. Assessing physical function in adult acquired major upper-limb amputees by combining the Disabilities of the Arm, Shoulder and Hand (DASH) Outcome Questionnaire and clinical examination. Arch Phys Med Rehabil. 2011;92(10):1636-45.

19. Kooijman CM, Dijkstra PU, Geertzen JH, Elzinga A, van der Schans CP. Phantom pain and phantom sensations in upper limb amputees: an epidemiological study. Pain. 2000:87:33-41.

20. Desmond DM, Maclachlan M. Prevalence and characteristics of phantom limb pain and residual limb pain in the long term after upper limb amputation. Int J Rehabil Res. 2010;33(3):279-82.

21. Østlie K, Lesjø IM, Franklin RJ, Garfelt B, Skjeldal OH, Magnus P. Prosthesis use in adult acquired major upper-limb amputees: patterns of wear, prosthetic skills and the actual use of prostheses in activities of daily life. Disabil Rehabil Assist Technol. 2012;7(6):479-93.

22. Rineer CA, Ruch DS. Elbow tendinopathy and tendon ruptures: epicondylitis, biceps and triceps ruptures. J Hand Surg [Am]. 2009:34:566-76.

23. Veeger HE, Rozendaal LA, van der Helm FC. Load on the shoulder in low intensity wheelchair propulsion. Clin Biomech (Bristol, Avon). 2002;17(3): 211-8.

24. Datta D, Selvarajah K, Davey N. Functional outcome of patients with proximal upper limb deficiency-acquired and congenital. Clin Rehabil. $2004 ; 18(2): 172-7$

\section{Submit your next manuscript to BioMed Central and we will help you at every step:}

- We accept pre-submission inquiries

- Our selector tool helps you to find the most relevant journal

- We provide round the clock customer support

- Convenient online submission

- Thorough peer review

- Inclusion in PubMed and all major indexing services

- Maximum visibility for your research

Submit your manuscript at www.biomedcentral.com/submit
Biomed Central 